\title{
BMJ
}

\section{Long term results of compression therapy alone versus compression plus surgery in chronic venous ulceration (ESCHAR): randomised controlled trial}

\author{
Manjit S Gohel, specialist registrar, Jamie R Barwell, consultant vascular and transplant surgeon, ${ }^{2}$ Maxine \\ Taylor, leg ulcer nurse specialist, ${ }^{1}$ Terry Chant, vascular nurse specialist, ${ }^{3}$ Chris Foy, medical statistician, ${ }^{4}$ \\ Jonothan J Earnshaw, consultant surgeon, ${ }^{5}$ Brian P Heather, consultant surgeon, ${ }^{5}$ David C \\ Mitchell, consultant surgeon, ${ }^{3}$ Mark R Whyman, consultant surgeon, ${ }^{1}$ Keith R Poskitt consultant surgeon ${ }^{1}$
}

${ }^{1}$ Cheltenham General Hospital, Cheltenham, Gloucester GL53 7AN 2Derriford Hospital, Plymouth

${ }^{3}$ Southmead Hospital, Bristol

${ }^{4}$ Gloucestershire Hospitals N

HS Trust, Gloucester

${ }^{5}$ Gloucestershire Royal Hospital, Gloucester

Correspondence to: $\mathrm{K}$ R Poskitt keith.poskitt@glos.nhs.uk

doi: 10.1136/bmi.39216.542442.BE

\section{ABSTRACT}

Objective To determine whether recurrence of leg ulcers may be prevented by surgical correction of superficial venous reflux in addition to compression.

Design Randomised controlled trial.

Setting Specialist nurse led leg ulcer clinics in three UK vascular centres.

Participants 500 patients ( 500 legs) with open or recently healed leg ulcers and superficial venous reflux.

Interventions Compression alone or compression plus saphenous surgery.

Main outcome measures Primary outcomes were ulcer healing and ulcer recurrence. The secondary outcome was ulcer free time.

Results Ulcer healing rates at three years were $89 \%$ for the compression group and $93 \%$ for the compression plus surgery group ( $P=0.73$, log rank test). Rates of ulcer recurrence at four years were $56 \%$ for the compression group and $31 \%$ for the compression plus surgery group ( $P<0.01)$. For patients with isolated superficial reflux, recurrence rates at four years were $51 \%$ for the compression group and $27 \%$ for the compress plus surgery group $(\mathrm{P}<0.01)$. For patients who had superficial with segmental deep reflux, recurrence rates at three years were $52 \%$ for the compression group and $24 \%$ for the compression plus surgery group $(\mathrm{P}=0.04)$. For patients with superficial and total deep reflux, recurrence rates at three years were $46 \%$ for the compression group and $32 \%$ for the compression plus surgery group $(\mathrm{P}=0.33)$. Patients in the compression plus surgery group experienced a greater proportion of ulcer free time after three years compared with patients in the compression group ( $78 \% \mathrm{~V}$ $71 \%$; $\mathrm{P}=0.007$, Mann-Whitney U test).

Conclusion Surgical correction of superficial venous reflux in addition to compression bandaging does not improve ulcer healing but reduces the recurrence of ulcers at four years and results in a greater proportion of ulcer free time.

Trial registration Current Controlled Trials ISRCTN07549334.

\section{INTRODUCTION}

In recent years the importance of the effect of venous leg ulceration on healthcare expenses and patients' quality of life has been recognised.$^{1-4}$ European studies have reported a prevalence of $1 \%$ in the adult population, increasing dramatically in those aged more than 80..$^{5-7}$ The precise pathophysiological mechanisms causing ulceration remain debatable, although chronic venous hypertension (usually as a result of venous reflux) is generally accepted to play a major part. ${ }^{58}$

Chronic venous hypertension may be countered by high elevation of the leg and multilayered compression bandaging, applied by trained staff within the setting of a specialist leg ulcer service. Excellent healing rates have been reported with this approach. ${ }^{9-11}$ Strategies to prevent ulcer recurrence include patient education and class 2 elastic compression stockings. ${ }^{12}$ Stockings are often difficult to put on and uncomfortable, however, resulting in poor patient compliance. ${ }^{13}$ Moreover, conservative approaches do little to correct the underlying problem of chronic venous hypertension.

Anatomical studies using colour venous duplex ultrasonography have shown that incompetence in superficial veins (long or short saphenous) is present in most legs with chronic ulceration, sometimes in combination with deep venous reflux. ${ }^{14-16}$ Isolated reflux in deep or perforating veins is uncommon. ${ }^{1516}$ Several surgical strategies to correct the underlying venous anatomical abnormalities have been attempted. Deep venous procedures may be associated with high complication rates, and studies have shown little clear benefit. ${ }^{17}$ However, several studies have suggested that corrective surgery for superficial venous reflux may have clinical benefits for ulcer healing and recurrence. ${ }^{18-20}$

The effect of surgery and compression on healing and recurrence (ESCHAR) study aimed to assess these outcomes in patients with chronic venous leg ulceration. The early results have been published and suggested that compression along with superficial venous surgery may reduce recurrence rates. ${ }^{21} \mathrm{We}$ present the long term findings. 


\section{METHODS}

The ESCHAR study started recruitment in January 1999 at three centres in south west England, serving a population of about 800000 . Since 1995 at two of the centres (Cheltenham General Hospital, Gloucestershire Royal Hospital) the management of leg ulcers has been directed by a specialist nurse led leg ulcer service. No such service existed at the third centre (Southmead Hospital), but the Gloucestershire model of leg ulcer care was extended to Southmead for the duration of this trial for recruited patients.

Referrals were received from community nursing teams, general practitioners, and other hospital medical specialists. Patients underwent a standardised leg ulcer assessment, consisting of medical history and clinical examination, assessment of ankle brachial pressure index, and colour venous duplex scanning. Routinely insonated segments included femoral vein, above and below knee popliteal vein, long and short saphenous veins, and calf perforating veins. We defined disease as being present if retrograde flow was more than one second after calf compression. Duplex scanning was carried out by trained vascular scientists. We assessed consecutive patients referred to the vascular services in the three centres and recruited those with open or recently healed leg ulceration (within six months) between knee and malleoli of greater than four weeks' duration, an ankle brachial

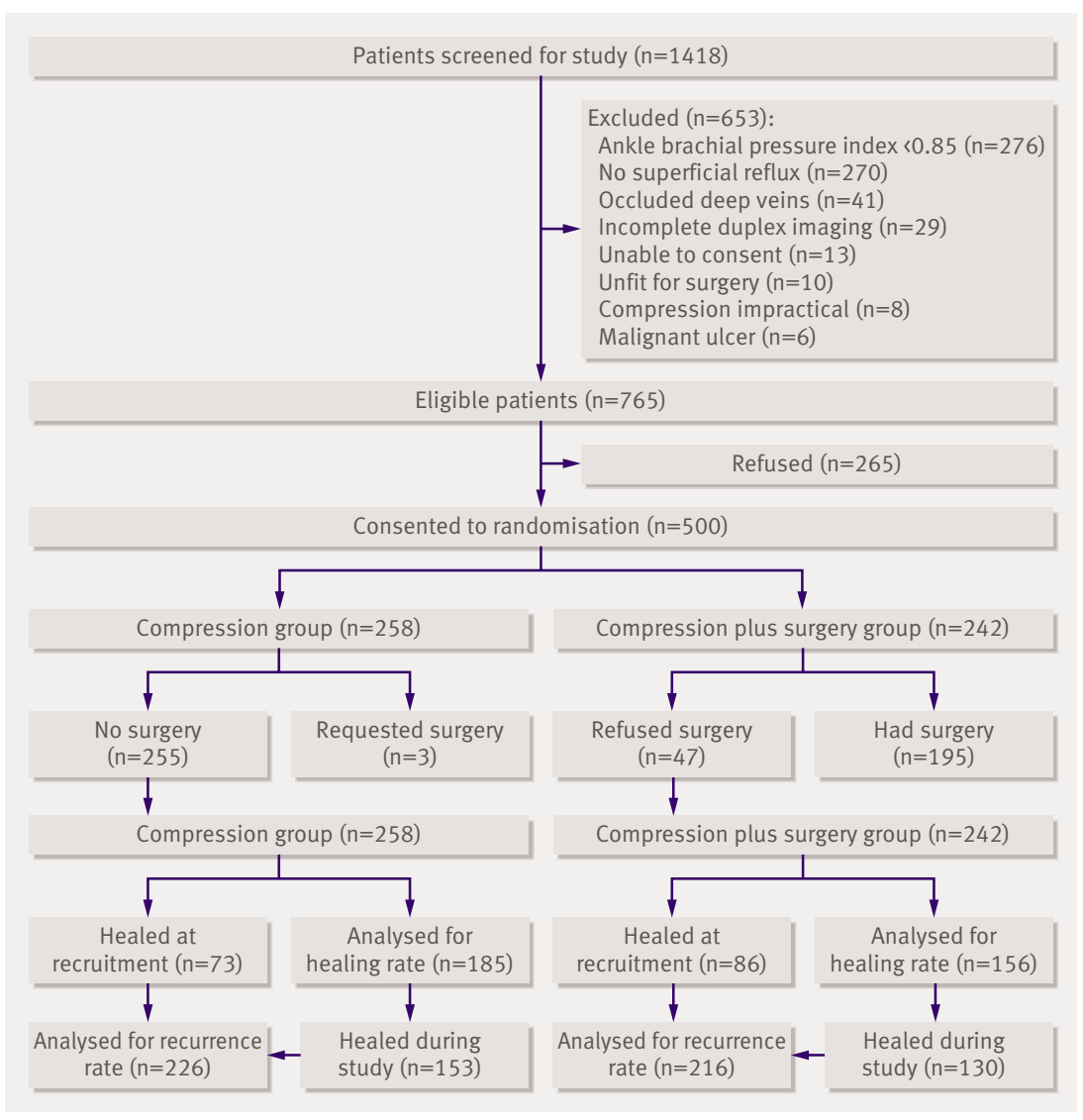

Fig 1 | Patient flow through trial pressure index of 0.85 or greater, and superficial or deep venous reflux on duplex scanning. We excluded patients in whom duplex scanning was not possible or multilayer compression therapy not practical, those who were unable or unwilling to give informed consent, those with deep venous occlusion, those unfit for surgery (even under local anaesthetic), and those with malignant ulceration. For the purposes of this study we classed patients without deep reflux as having isolated superficial reflux. Patients with reflux in some, but not all, deep veins were described as having superficial and segmental deep reflux, whereas patients with reflux throughout the deep system were described as having superficial and total deep reflux. The diagnosis of superficial venous reflux was made purely on findings from duplex scans rather than the presence of visible varicosities.

If patients had ulceration of both legs, we studied the clinically worse leg, as decided by the patient. Treatment was the same for both legs. Written informed consent was obtained from the patients.

\section{Randomisation and treatments}

Patients were randomly allocated to treatment with multilayered compression therapy alone or compression plus superficial venous surgery. Computer generated random numbers were sealed in sequentially numbered envelopes and group allocation was independent of time, place, and person delivering the treatment.

\section{Compression therapy}

Patients with open ulceration were treated weekly with multilayered compression bandaging (Smith \& Nephew, Hull) aiming for $40 \mathrm{~mm} \mathrm{Hg}$ of pressure at the ankle graduated to $17-20 \mathrm{~mm} \mathrm{Hg}$ at the upper calf. Patients with healed legs were prescribed class 2 elastic stockings (Medi, Hereford) and advised to wear these during the day. All patients were given standard written and verbal advice to elevate the affected leg and to exercise.

\section{Surgical treatments}

Patients randomised to compression plus surgery were offered superficial venous surgery guided by findings on duplex scans. Patients with reflux at the saphenofemoral junction or long saphenous vein were offered saphenofemoral junction disconnection, stripping of the long saphenous vein to below the knee, and calf varicosity avulsions. Venous reflux in the short saphenous vein was treated with saphenopopliteal junction disconnection and calf varicosity avulsions. We treated patients who were considered unfit for general anaesthesia with saphenofemoral or saphenopopliteal junction disconnections, or both, under local anaesthetic.

\section{Follow-up and outcome measures}

Patients with open ulceration were reviewed monthly in the clinics until ulceration had healed, or more often if clinically necessary. After healing, patients were reviewed at one month then every three months for 
one year and every six months thereafter. Patients were given instructions to contact the service immediately for possible ulcer recurrence. After recurrence, intensive follow-up was continued to three years in two of the centres (Cheltenham and Gloucester) when details of further episodes of ulcer healing and rerecurrence were recorded.

Primary outcome measures were ulcer healing and ulcer recurrence. Ulcer free time was assessed as a secondary outcome measure. Ulcer healing was defined as complete re-epithelialisation of the leg. We classified any breakdown of epithelium between knee and malleoli after ulcer healing as ulcer recurrence. Ulcer free time was defined as the total time with a healed leg and was calculated to three years.

\section{Statistical analysis}

We calculated the sample size using previous non-randomised study data for ulcer recurrence rates at 12 months. Details have been published previously. ${ }^{21}$ Allowing a wide margin for mortality, losses to followup, protocol violations, non-healing ulcers, and extended follow-up, we estimated a recruitment target of 500 patients. Analyses were carried out on an intention to treat basis with no per protocol analyses planned. We calculated ulcer healing and recurrence using Kaplan-Meier survival analysis with log rank comparisons. For the purposes of the Kaplan-Meier analysis we took time zero as the date of recruitment for patients with healed legs and date of healing for patients recruited with open ulceration. We planned subgroup analyses for patients with isolated superficial reflux, superficial with segmental deep reflux, and superficial with total deep reflux. Tests for interaction were carried out using Cox regression analysis. All analyses were carried out using SPSS for windows version 13.0.1, with $\mathrm{P}$ values less than 0.05 considered as significant.

\section{RESULTS}

Between January 1999 and August 2002, 1418 consecutive patients with open or recently healed leg ulcers and superficial venous reflux were screened for inclusion in the study, of whom 500 consented (fig 1). A total of 258 patients were randomly allocated to compression alone and 242 to compression plus surgery. Fifty four patients were lost to follow-up or withdrew from the trial (27 compression, 27 compression plus surgery) and were censored from Kaplan-Meier analyses. Forty seven patients randomised to compression plus surgery did not attend for surgery and three randomised to compression requested surgery.

The groups were well matched for age, sex, ulcer chronicity, and ulcer size (table 1). Of the 500 patients, 300 had isolated superficial reflux, 126 had superficial with segmental deep reflux, and 74 had superficial with total deep reflux. Overall mortality was $17 \%$ at three years, with the groups showing similar mortality $(19 \%$ compression, $16 \%$ compression plus surgery; $\mathrm{P}=0.245$, $\log$ rank test). No deaths occurred within 30 days of surgery or as a direct result of surgery.
Baseline characteristics of patients with open or recently healed ulcers and superficial venous reflux by treatment group. Values are medians (interquartile ranges) unless stated otherwise

\begin{tabular}{|c|c|c|}
\hline Characteristic & $\begin{array}{l}\text { Compression } \\
\text { alone }(n=258)\end{array}$ & $\begin{array}{l}\text { Compression plus } \\
\text { surgery }(n=242)\end{array}$ \\
\hline Age (years) & $72(60-79)$ & $74(60-80)$ \\
\hline No $(\%)$ of men & $114(44)$ & $98(40)$ \\
\hline Ulcer diameter $(\mathrm{cm})$ & $2(1-4)$ & $2(1-5)$ \\
\hline Ulcer chronicity (months) & $5(3-11)$ & $5(3-11)$ \\
\hline No (\%) with diabetes & $27(10)$ & $12(5)$ \\
\hline $\begin{array}{l}\text { No (\%) with previous deep } \\
\text { vein thrombosis* }\end{array}$ & $26(10)$ & $19(8)$ \\
\hline
\end{tabular}

Of 242 patients randomised to compression plus surgery, $195(81 \%)$ attended for their operation; surgery was carried out to the long saphenous vein in 141 (72\%), the short saphenous vein in $27(14 \%)$, and both the long and the short saphenous veins in $21(11 \%)$. Six patients $(3 \%)$ underwent calf perforator surgery only. Surgical complications were seen in eight patients, as reported previously. ${ }^{21}$ Temporary hospital admission was necessary in two cases.

\section{Ulcer healing}

Overall ulcer healing rates at three years were $89 \%$ in the compression group and $93 \%$ in the compression plus surgery group $(\mathrm{P}=0.737, \log$ rank test; fig 2$)$. Numbers were too small to calculate healing rates at three years for the subgroups stratified by venous reflux pattern. Analysis for interaction showed that the effect of surgery on healing did not differ between the subgroups stratified by venous reflux $(\mathrm{P}=0.053$, hazard ratio $0.756,95 \%$ confidence interval 0.513 to 1.004 ).

\section{Ulcer recurrence}

Ulcer recurrence rates at four years were significantly lower in the compression plus surgery group

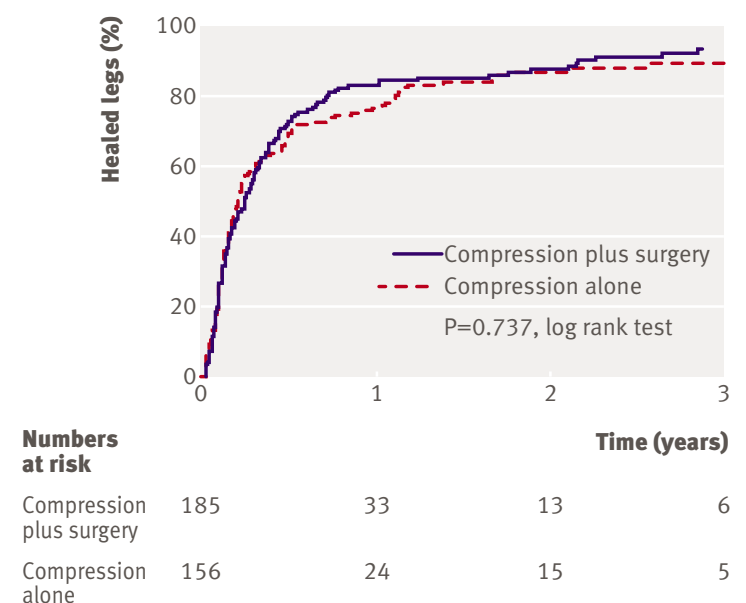

Compression 156 alone

Fig 2 | Kaplan-Meier survival analysis showing ulcer healing at three years 


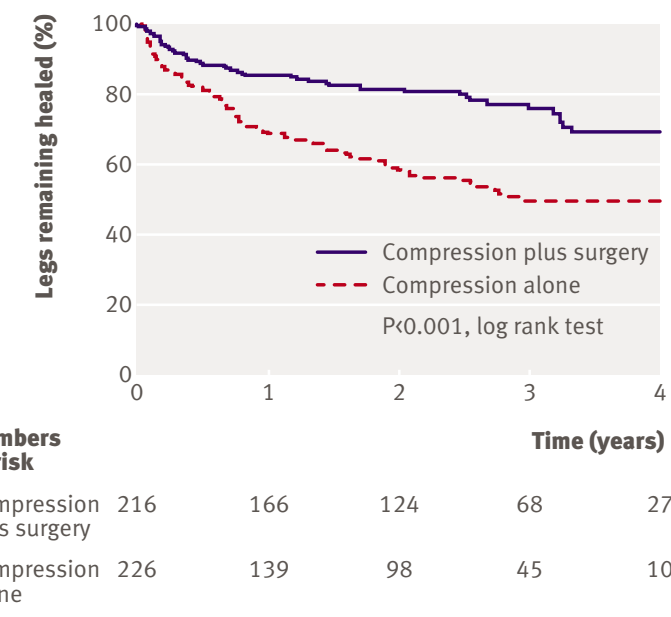

Fig 3 | Kaplan-Meier survival analysis showing ulcer recurrence at four years

compared with the compression group (31\% v 56\%; $\mathrm{P}<0.001$, log rank test; fig 3). For patients with isolated superficial reflux, recurrence rates at four years were $27 \%$ in the compression group and $51 \%$ in the compression plus surgery group $(\mathrm{P}<0.001$; fig 4$)$. For patients with superficial plus segmental deep reflux, recurrence rates at three years were $24 \%$ in the compression plus surgery group and $52 \%$ in the compression group $(\mathrm{P}=0.044 ;$ fig 4$)$. For patients with superficial plus total deep reflux, recurrence rates at three years were $24 \%$ in the compression plus surgery group and $46 \%$ in the compression group, although this was not a statistically significant finding $(\mathrm{P}=0.23$; fig 4). Cox regression analysis confirmed that randomisation to surgery significantly reduced ulcer recurrence $(\mathrm{P}<0.001$, hazard ratio $2.926,95 \%$ confidence interval 1.723 to 4.133 ), although the influence of surgery on recurrence was not shown to differ between the subgroups with differing patterns of venous reflux
$(\mathrm{P}=0.227$, hazard ratio $0.833,95 \%$ confidence interval 0.479 to 1.191$)$.

\section{Ulcer free time}

Ulcer free time was assessed to three years in 365 of the $500(73 \%)$ patients. Patients randomised to compression plus surgery experienced significantly longer absolute (100 $v 85$ weeks, $\mathrm{P}=0.013)$ and proportional $(78 \%$ v $71 \%, \mathrm{P}=0.007)$ ulcer free time up to three years than those randomised to compression. A total of 122 episodes of recurrent ulceration occurred during the study; 81 in the compression group compared with 41 in the compression plus surgery group $(\mathrm{P}=0.001$, Mann-Whitney $\mathrm{U}$ test $)$.

\section{DISCUSSION}

Superficial venous surgery in addition to compression therapy for chronic venous leg ulceration reduced ulcer recurrence and improved ulcer free time when compared with compression alone. In accordance with previous, smaller studies, the clinical benefit seemed greatest for patients with isolated superficial reflux $^{18-20}$ but was also present for patients with coexistent segmental deep reflux. For patients with isolated superficial reflux, four would need to undergo surgery to prevent one episode of ulceration in four years.

Although the improvement in ulcer recurrence rates was less impressive in the groups with segmental and total deep reflux, the subgroups were smaller and the actual benefit of surgery may have been underestimated. Other authors have reported reversal of venous reflux in deep and perforating veins after superficial venous surgery, ${ }^{22-24}$ and postoperative duplex scans of patients in our study showed a similar effect. ${ }^{2526}$ Therefore deep venous reflux should not be considered an absolute contraindication to superficial venous surgery as patients may experience significant haemodynamic and clinical benefits. Ulcer healing was not improved by superficial venous surgery possibly because the haemodynamic benefit of multilayer

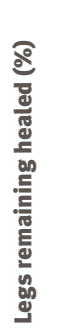

Isolated superficial reflux

0
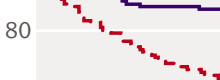

60

40
Superficial with segmental deep reflux

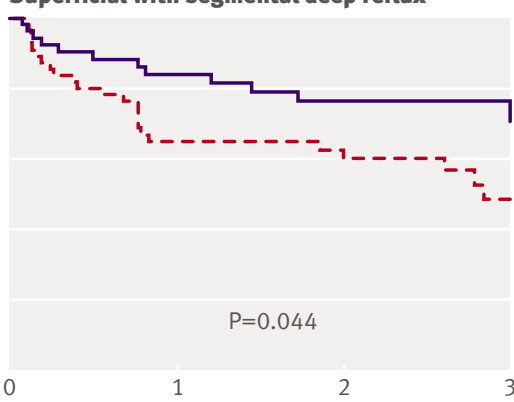
Time (years)

Time (years)

Numbers

at risk

Compression 133

plus surgery

Compression 140

alone

20

$0_{0}$

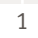

2
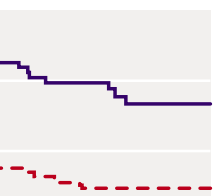

- Compression plus surgery

- Compression alone

107

83

90

63

Superficial with total deep reflux

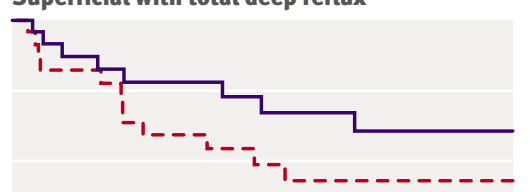

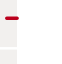
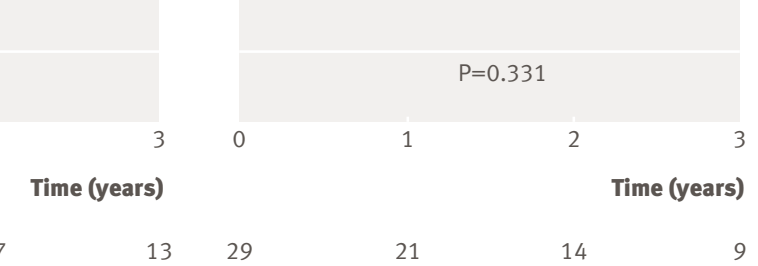

38

32

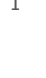




\section{WHAT IS ALREADY KNOWN ON THIS TOPIC}

Chronic venous ulceration is a common and expensive clinical problem

Venous reflux in superficial veins is commonly seen in these patients

\section{WHAT THIS STUDY ADDS}

Surgical correction of superficial venous reflux in addition to compression bandaging does not improve ulcer healing rates

Surgical correction can, however, reduce the chance of recurrent ulceration and increase ulcer free time and others underwent surgery under local anaesthetic without stripping of the long saphenous vein. Factors other than venous reflux, such as coexisting medical problems or ankle stiffness causing poor calf muscle function, ${ }^{34}$ may have contributed to recurrent ulceration in individual cases. Whether these patients experienced more ulcer free time after surgery as a result of less frequent or shorter episodes of recurrent ulceration remains unproved. Nevertheless, residual venous reflux and neovascularisation are common after superficial venous procedures, and stripping of the long saphenous vein to the knee is preferable..$^{35}$

compression bandaging was not significantly improved by the addition of surgery. ${ }^{2728}$

Strengths and weaknesses of the study

Our study was set within an established leg ulcer service across three vascular centres, and we considered consecutive patients. Inclusion criteria were deliberately open and surgery was carried out by competent surgeons of varying grades consistent with standard patient care. The study was designed to emulate standard clinical practice to ensure that results could be widely applicable to the patient population with leg ulceration. Our choice of surgery and patient stratification were based solely on findings from colour venous duplex scanning. Other studies have suggested that non-invasive assessment of venous refill time using photoplethysmography may help predict success after surgery. ${ }^{29}$ Further refinement of the selection process could improve the identification of patients most likely to derive a clinical benefit from the addition of venous surgery.

Poor compliance with surgical treatment for patients with leg ulceration has been reported. ${ }^{30}$ In our study $24 \%$ of patients randomised to surgery refused to attend for their operation despite extensive counselling before recruitment. Moreover, patients waited a median of seven weeks for their operation and therefore may not have received an immediate benefit. Despite these factors we carried out all analyses on an intention to treat basis, suggesting that the benefits of surgery may have been underestimated. In recent years several less invasive procedures for the treatment of superficial venous reflux have been forwarded, including foam sclerotherapy, ${ }^{31}$ radiofrequency ablation, ${ }^{32}$ and endovenous laser. ${ }^{33}$ These techniques, often carried out under local anaesthetic, may have a role for patients reluctant to undergo traditional surgery, although long term durability remains unproved.

Class 2 stockings have been shown to reduce ulcer recurrence and we prescribed them for all patients after ulcer healing. ${ }^{12}$ We did not formally assess compliance with stocking use, although patients were given similar written and verbal advice. Other authors have reported poor compliance with stocking use, ${ }^{13}$ which may partly explain the high incidence of recurrent ulceration without surgery $(56 \%$ at four years in this study). Of the patients randomised to compression plus surgery, $31 \%$ had recurrent ulceration within four years. Some did not attend for their operation

\section{Future research}

The recent introduction of novel, endovenous techniques for the correction of venous incompetence may provide a more acceptable treatment option for elderly patient groups with chronic venous ulceration. ${ }^{31-33}$ Further studies are needed to ascertain the haemodynamic benefits, durability, and clinical efficacy of these techniques compared with traditional venous surgery. Further work is also needed to help identify those patients who would benefit most from correction of venous incompetence and to determine why some patients experience recurrence despite the abolition of reflux.

\section{Conclusions}

Chronic leg ulceration is common and distressing for patients and an important financial burden for healthcare providers. These long term findings support the early results from the effect of surgery and compression on healing and recurrence study and present a cogent argument for the widespread provision of colpatients with chronic venous leg ulcers.

We thank for their support and assistance CE Davies, G Turton, G Woolfrey, J Waldron (Gloucestershire Leg Ulcer Service); C Wakely, J Minor, K Harvey, A Sassano (vascular scientists); and B Whitman (research assistant).

Contributors: MG was involved with data acquisition, management and analysis, and wrote this report. JB, JE, MW, and KP were involved with study concept and design, performed surgery, and critically revised this report. BH and DM performed surgery, were involved with data acquisition, and critically revised this report. MT, TC were involved with data acquisition, and critically revised this report. CF provided statistical guidance and critically revised this report.

Funding: NHS Executive South and West Research and Development Directorate, Southmead Hospital Research Foundation, and Medical Research Council. The funding sources had no financial or other interest in study outcome and had no role in study design, data control or reporting.

Competing interests: None declared.

Ethical approval: Gloucestershire and Southmead research ethics committees.

1 Ragnarson-Tennvall G, Hjelmgren J. Annual costs of treatment for venous leg ulcers in Sweden and the United Kingdom. Wound Repair Regen 2005;13:13-8.

2 Nelzen O. Leg ulcers: economic aspects. Phlebology 2000;15:110-4.

3 Charles H. Does leg ulcer treatment improve patients' quality of life?J Wound Care 2004;13:209-13. quality of life during four-layer compression bandaging for venous ulcer disease: a randomised controlled trial. Ir J Med Sci 2005;174:21-5 our duplex scanning and superficial venous surgery for

4 Clarke-Maloney M, O'Brien JF, Grace PA, Burke PE. Health-related 
5 Ruckley CV, Evans CJ, Allan PL, Lee AJ, Fowkes FG. Chronic venous insufficiency: clinical and duplex correlations. The Edinburgh vein study of venous disorders in the general population. J Vasc Surg 2002;36:520-5.

6 Nelzen O, Bergqvist D, Lindhagen A. The prevalence of lower-limb ulceration has been underestimated: results of a validated population questionnaire. Br J Surg 1996;83:255-8.

7 Carpentier PH, Maricq HR, Biro C, Poncot-Makinen CO, Franco A. Prevalence, risk factors, and clinical patterns of chronic venous disorders of lower limbs: a population based study in France. I Vasc Surg 2004;40:650-9.

8 Nicolaides AN, Hussein MK, Szendro G, Christopoulos D, Vasdekis S, Clarke $\mathrm{H}$. The relation of venous ulceration with ambulatory venous pressure measurements. J Vasc Surg 1993;17:414-9.

9 Ghauri AS, Taylor MC, Deacon JE, Whyman MR, Earnshaw JJ, Heather BP, et al. Influence of a specialised leg ulcer service on management and outcome. Br / Surg 2000;87:1048-56.

10 Moffatt CJ, Franks PJ, Oldroyd M, Bosanquet N, Brown P, Greenhalgh RM, et al. Community clinics for leg ulcers and impact on healing. BMJ 1992;305:1389-92.

11 Morrell CJ, Walters SJ, Dixon S, Collins KA, Brereton LM, Peters J, et al. Cost effectiveness of community leg ulcer clinics: randomised controlled trial. BMJ 1998;316:1487-91.

12 Nelson EA, Bell-Syer SE, Cullum NA. Compression for preventing recurrence of venous ulcers. Cochrane Database Syst Rev 2000;(4): CD002303.

13 Harper D, Nelson E, Gibson B, Prescott R, Ruckley CV. A prospective randomised trial of class 2 and class 3 elastic compression in the prevention of venous ulceration. Phlebology 1995;(suppl 1):872-3.

14 Magnusson MB, Nelzen O, Risberg B, Sivertsson R. A colour doppler ultrasound study of venous reflux in patients with chronic leg ulcers. Eur J Vasc Endovasc Surg 2001;21:353-60.

15 Hanrahan LM, Araki CT, Rodriguez AA, Kechejian GJ, LaMorte WW, Menzoian JO. Distribution of valvular incompetence in patients with venous stasis ulceration. J Vasc Surg 1991;13:805-11.

16 Grabs AJ, Wakely MC, Nyamekye I, Ghauri AS, Poskitt KR. Colour duplex ultrasonography in the rational management of chronic venous leg ulcers. Br J Surg 1996;83:1380-2.

17 Hardy SC, Riding G, Abidia A. Surgery for deep venous incompetence. Cochrane Database Syst Rev 2004;(3):CD001097.

18 Zamboni P, Cisno C, Marchetti F, Mazza P, Fogato L, Carandina S, et al. Minimally invasive surgical management of primary venous ulcers vs. compression treatment: a randomised clinical trial. Eur J Vasc Endovasc Surg 2003;25:313-8.

19 Darke SG, Penfold C. Venous ulceration and saphenous ligation. Eur Vasc Surg 1992;6:4-9.

20 Barwell JR, Taylor M, Deacon J, Ghauri AS, Wakely C, Phillips LK, et al. Surgical correction of isolated superficial venous reflux reduces longterm recurrence rate in chronic venous leg ulcers. EurJ Vasc Endovasc Surg 2000;20:363-8.

21 Barwell JR, Davies CE, Deacon J, Harvey K, Minor J, Sassano A, et al. Comparison of surgery and compression with compression alone in chronic venous ulceration (ESCHAR study): randomised controlled trial. Lancet 2004;363:1854-9.
22 MacKenzie RK, Allan PL, Ruckley CV, Bradbury AW. The effect of long saphenous vein stripping on deep venous reflux. Eur J Vasc Endovasc Surg 2004;28:104-7.

23 Walsh JC, Bergan JJ, Beeman S, Comer TP. Femoral vein reflux abolished by greater saphenous vein stripping. Ann Vasc Surg 1994;8:566-70

24 Adam DJ, Bello M, Hartshorne T, London NJ. Role of superficial venous surgery in patients with combined superficial and segmental deep venous reflux. Eur I Vasc Endovasc Surg 2003;25:469-72.

25 Gohel MS, Barwell JR, Wakely C, et al. The influence of superficial venous surgery and compression on incompetent calf perforators in chronic venous leg ulceration. Eur J Vasc Endovasc Surg 2005;29:78-82.

26 Gohel MS, Barwell JR, Earnshaw J), Heather BP, Mitchell DC, Whyman MR, et al. Randomized clinical trial of compression plus surgery versus compression alone in chronic venous ulceration (ESCHAR study) - haemodynamic and anatomical changes. Br/Surg 2005;92:291-7.

27 Guest M, Smith JJ, Tripuraneni G, Howard A, Madden P, Greenhalgh RM, et al. Randomized clinical trial of varicose vein surgery with compression versus compression alone for the treatment of venous ulceration. Phlebology 2003;18:130-6.

28 Guest M, Smith J), Sira MS, Madden P, Greenhalgh RM, Davies AH. Venous ulcer healing by four-layer compression bandaging is not influenced by the pattern of venous incompetence. $\mathrm{Br} / \mathrm{Surg}$ 1999;86:1437-40

29 Sullivan JG, Ghauri ASK, Whyman MR, Poskitt KR. Preoperative digital photoplethysmography predicts improvement in venous function after superficial venous surgery for chronically ulcerated limbs. Phlebology 1998;13:142-7.

30 Ghauri AS, Nyamekye I, Grabs AJ, Farndon IR, Whyman MR, Poskitt KR. Influence of a specialised leg ulcer service and venous surgery on the outcome of venous leg ulcers. Eur J Vasc Endovasc Surg 1998;16:238-44.

31 Pascarella L, Bergan JJ, Mekenas LV. Severe chronic venous insufficiency treated by foamed sclerosant. Ann Vasc Surg 2006;20:83-91.

32 Lurie F, Creton D, Eklof B, Kabnick LS, Kistner RL, Pichot O, et al. Prospective randomized study of endovenous radiofrequency obliteration (closure procedure) versus ligation and stripping in a selected patient population (EVOLVeS Study). J Vasc Surg 2003;38:207-14.

33 Sharif MA, Soong CV, Lau LL, Corvan R, Lee B, Hannon RJ. Endovenous laser treatment for long saphenous vein incompetence. BrJ Surg 2006;93:831-5.

34 Dix FP, Brooke R, McCollum CN. Venous disease is associated with an impaired range of ankle movement. Eur J Vasc Endovasc Surg 2003;25:556-61.

35 Winterborn RJ, Foy C, Earnshaw JJ. Causes of varicose vein recurrence: late results of a randomised controlled trial of stripping the long saphenous vein. J Vasc Surg 2004;40:634-9.

Accepted: 26 April 2007 